\title{
Dampak Pembangunan Modern Terhadap Keberadaan Situs Buni
}

\author{
Husein Abdurrahim*, I Nyoman Wardi, Zuraidah \\ Prodi Arkeologi, Fakultas Ilmu Budaya, Unud \\ [husein.abdurrahim@gmail.com] [wardiecoculture@gmail.com] [ida_arkeounud@yahoo.com] \\ Bekasi, Jawa Barat, Indonesia \\ *Corresponding Author
}

\begin{abstract}
Buni site is one of the prehistoric relics in Bekasi Regency which has an important role for the development of history in the northern part of Java Island. There are several potential archeological remains at the Buni Site in the form of metal artifacts, stone axes, gold jewelery, beads, earthenware and conch shells. The existence of modern development around the Buni Site makes the Buni Site threatened its preservation. There are two modern developments flanking the Buni Site, which is a ship factory managed by PT. Tesco Indomaritim and PLTU (Steam Power Plant) managed by PT. Cikarang Listrikindo. This study aims to address the formulation of the problem the impact of modern development on the existence of the Buni Site and conservation efforts at the Buni Site. This study use the Archeology Resource Management theory. Data collection methods used were observation, literature study, and interviews. Data analysis techniques used ware qualitative and SWOT. There are two impacts given by modern development on the Buni Site. First, the damage and lost of the Buni site, the lost of the site area has made the Buni site narrow and lost the findings that have the potential to be left behind in the area of the ship factory and the power plant. Secondly, Muara Bakti Village, where Buni Site is located, is no longer known by the wider community as the Archaeological Site. Buni site is currently not used as a cultural heritage site, which can affect its preservation. Development of the Buni Site area as a tourist attraction, in the form of the Buni Cultural Museum can help preserve the Buni Site from damage.
\end{abstract}

Keywords: buni site, modern development impact, conservation archaeology.

\begin{abstract}
Abstrak
Situs Buni merupakan salah satu peninggalan prasejarah di Kabupaten Bekasi yang mempunyai peran penting bagi perkembangan sejarah di Pulau Jawa bagian Utara. Terdapat beberapa potensi tinggalan arkeologi di Situs Buni berupa artefak logam, kapak batu, perhiasan emas, manik-manik, gerabah, dan kulit kerang. Adanya pembangunan modern di sekitar Situs Buni membuat Situs Buni terancam pelestariannya. Terdapat dua pembangunan modern yang mengapit Situs Buni, yaitu pabrik kapal yang dikelola oleh PT. Tesco Indomaritim dan PLTU (Pembangkit Listrik Tenaga Uap) yang dikelola oleh PT. Cikarang Listrikindo. Penelitian ini bertujuan untuk menjawab rumusan masalah yaitu dampak pembangunan modern terhadap keberadaan Situs Buni upaya pelestarian di Situs Buni. Penelitian ini menggunaka teori Manajemen Sumberdaya Arekologi. Metode pengumpulan data yang digunakan adalah observasi, studi pustaka, dan wawancara. Teknik analisis data yang digunakan yaitu kualitatif dan SWOT. Terdapat dua dampak yang diberikan pembangunan modern terhadapa Situs Buni. Pertama rusak dan hilangnya Situs Buni, Menghilannya kawasan Situs tersebut menjadikan Situs Buni menyempit dan kehilangan temuan-temuan yang berpotensi tertinggal di areal pabrik kapal dan PLTU tersebut. Kedua Desa Muara Bakti yang merupakan tempat Situs Buni berada tidak lagi
\end{abstract}


dikenal oleh masyarakat luas sebagai Situs Arkeologi. Situs Buni saat ini belum dijadikan sebagai situs cagar budaya, yang bisa bedampak pada pelestariannya. Pembangunan kawasan Situs Buni menjadi objek wisata, berupa Museum Budaya Buni dapat membantu pelestarian Situs Buni dari kerusakan.

Kata kunci: situs buni, dampak pembangunan modern, pelestarian arkeologi.

\section{PENDAHULUAN}

Daerah Jakarta, Bogor, Depok, Tanggerang, dan Bekasi mempunyai banyak temuan prasejarah. Lokasi-lokasi prasejarah di Jakarta dan sekitarnya dapat diketahui dari informasi penduduk yang memperoleh temuan kemudian menyerahkannya ke Museum Nasional. Temuan prasejarah yang menjadi koleksi museum tersebut tercatat dalam Catalogus der Praehistoriche Verzamaling yang ditulis oleh van der Hoop (1941). Berdasarkan catatan van der Hoop dan laporan masyarakat ada 81 lokasi temuan dan 39 lokasi tersebut telah dilakukan penelitan, baik berupa survey maupun eskavasi (Akbar, 2007:27). Salah satu dari 39 lokasi temuan prasejarah yang telah diteliti adalah Situs Buni yang terletak di Kampung Buni Pasar Emas, Desa Buni Bakti, Kecamatan Babelan, Kabupaten Bekasi, Provinsi Jawa Barat. Ketinggian $23 \mathrm{~m}$ di atas permukaan laut. Situs Buni berada di sebelah barat sungai Bekasi. Dalam catatan yang dibuat oleh Hoop (Catalogus der Praehistoriche Verzamaling, 1941), daerah ini merupakan salah satu lokasi yang mengandung temuan prasejarah, yakni beliung persegi (Akbar, 2007:71)

Situs Buni pertama kali diteliti oleh R.P Soejono dan Basuki dari Puslit Arkenas pada Maret dan April 1960 untuk mengetahui situs-situs yang berada di sana. Penelitian itu berupa eskavasi percobaan dan hasilnya menunjukkan lokasi yang sudah hancur oleh penggalian liar serta temuan sudah bercampur aduk. Penelitian di Situs Buni menghasilkan temuan prasejarah berupa tembikar dari berbagai jenis bentuk dan ukuran (periuk, tempayan, cawan berkaki dan kendi), beliung persegi, artefak dari perunggu (kapak) dan besi (parang), gelang kaca dan batu, perhiasan emas (penutup mata dan mulut), manik-manik, bandul jaring terakota, dan tulang manusia (Djafar, 2016).

Temuan-temuan dari Situs Buni berdasarkan hasil penelitian 1977 dan 1978 kini sebagian masih dapat dilacak keberadaanya dan menjadi koleksi Puslit Arkenas. Koleksi Puslit Arkenas sesuai dengan daftar buku induk artefak berjurnlah 758, berupa 747 fragmen tembikar (polos dan berhias), empat fragmen artefak besi, dan tujuh artefak besi (Akbar, 2007:7).

Benda-benda tinggalan arkeologi yang ada di Situs Buni beberapa ada di rumah penduduk. Disimpan oleh tokoh masyarakat Desa Buni, benda-benda tinggalan itu diletakkan dalam wadah ember dan piring. Pemilik menyimpan barang tinggalan di wadah ember dan piring karena ketidak tahuannya tentang pelestarian tinggalan arkeologi dan juga keadaan keuangan yang memaksanya meletakka barang-barang tersebut begitu saja.

Keadaan Situs Buni diperparah dengan terbengkalainya situs bertahuntahun tanpa adanya tidak lanjut dari pihak yang berwenang. Situs Buni saat ini terlihat seperti desa kebanyakan, tidak adanya penanganan sebagaimana situs arkeologi lainnya, seperti adanya papan penunjuk Situs Arkeologi dan papan penjunjuk jalan ke situs. Tanpa adanya perlakuan khusus sebagai situs arkeologi, situs Buni dipenuhi oleh rumah-rumah 
warga, sawah, PLTU di bagian selatan dan pabrik serta pabrik kapal di bagian utara Situs Buni. Terdapat dua pembangunan modern yang mengapit Situs Buni yaitu, pabrik kapal yang dikelola oleh PT. Tesco Indomaritim dan PLTU (Pembangkit Listrik Tenaga Uap) yang dikelola oleh PT. Cikarang Listrikindo.

Indonesia mempunyai regulasinya sendiri yang mengatur tentang benda arkeologi yang berada dalam wilayah republik Indonesia. Regulasi tersebut tertuang dalam UU No.11 tahun 2010, undang-undang tersebut merupakan revisi dari UU no.5 tahun 1992 yang dianggap tidak relevan lagi pada saat ini.

Pelestarian Situs Arkeologi dan benda-benda arkeologi di Situs Buni harus dilakukan, mengingat Situs Buni merupakan situs penting dalam perkembangan kebudayaan masyarakat pesisir Utara Jawa bagian barat. Masyarakat mempunyai peran penting dalam pelestarian ini sebagai pemilik Situs dan benda-benda arkelogi yang ada di Situs Buni (Ahimsa, 2017:20).

Sejak diteliti oleh R.P Soejono dan Besuki dari Puslit Arkenas tahun 1961 Situs Buni belum ditetapkan menjadi situs cagar budaya. Jika dilihat UU cagar budaya tahun 2010 Situs Buni sudah dapat dijadikan cagar budaya. Adanya pabrik PT Tesco indomaritim dan PLTU PT Cikarang Listrikindo semakin membuat situs Buni terancam sebagai situs arkeologi (Mantitaputy. 2010:30).

Tujuan artikel ini adalah Untuk mengetahui dampak pembangunan modern terhadap Situs Buni di Kabupaten Bekasi, Serta Untuk mengetahui strategi pelestarian yang tepat di Situs Buni di Kabupaten Bekasi.

\section{METODE}

Penelitian ini menggunakan teori Manajemen Sumberdaya Arkeologi (Suroto, 2009:28). Teori Manajemen Sumberdaya Arkeologi digunakan untuk mengembankan serta memanfaatkan potensi yang terdapat di Situs Buni sehingga dapat mengetahui tentang pelestarian yang tepat untuk diterapkan.

Penelitian ini juga menggunakan beberapa metode analisis untuk mengolah data yang didapatkan. Analisis yang digunakan yaitu analisis kualitatif (Koentjaraningrat. 1986; 98) dan analisis SWOT. Analisis kualitatif digunakan untuk menguraikan terkait potensi sumberdaya arkeologi di Situs Buni, pelestarian Situs Buni dan dampak dari pabrik kapal dan PLTU. Analisis SWOT digunakan untuk mengidentifikasi startegi yang memungkinkan untuk dilakukan dengan memanfaatkan peluang yang ada, dengan kekuatan yang dimiliki dan memperbaiki kelemahan untuk mengatasi ancaman yang mungkin terjadi untuk pelestarian Situs Buni (Rangkuti, 1996:23).

\section{HASIL DAN PEMBAHASAN}

\section{Gambaran Umum Situs Buni, PT Tesco Indomaritim dan PT Cikarang Listrikindo}

Penamaan Situs Buni diambil dari nama desa tempat ditemukannya bendabenda arkeologi, yaitu Desa Buni Bakti. Seiring berjalannya waktu, Desa Buni Bakti mengalami pemekaran administrasi sehingga mengakibatkan munculnya desa baru yang bernama Desa Muara Bakti. Secara administrasi, Situs Buni saat ini berada diantara perbatasan dua desa tersebut. Sebagian besar tinggalan yang ditemukan di Situs Buni berada di Desa Muara Bakti. Sebagian lagi di wilayah Desa Buni Bakti.

Situs Buni telah diketahui sejak tahun 1937. Bermula dari penjual barangbarang antik yang menjual barang dari Desa Buni, Bekasi. Situs Buni makin dikenal saat ditemukannya perhiasan emas pada tahun 1958. Informasi penemuan tersebut mengakibatkan terjadinya penggalian liar yang dilakukan 
oleh masyarakat, bahkan orang-orang dari luar Bekasi. Mereka berdatangan untuk ikut dalam penggalian liar tersebut.

Pemerintah pun melindungi lokasi ini untuk mencegah adanya penggalian liar terjadi kembali. Penelitian di Situs Buni kembali dilanjutkan pada 1964, 1969, 1970. Dari penelitian di Situs Buni dapat di ketahui bahwa terdapat tembikar dari berbagai jenis bentuk dan ukuran (periuk, tempayan, cawan berkaki dan kendi), beliung persegi, artefak dari perunggu (kapak) dan besi (parang), gelang kaca dan batu, perhiasan emas (penutup mata dan mulut), manik-manik, bandul jaring terakota, sisa-sisa makanan dan tulang manusia.

PT Tesco Indomaritim adalah perusahaan pembuat kapal yang berkualitas dan kapal plat baja dan aluminium. Pada tahun 1990 PT. Tesco mendirikan pabrik kapalnya di desa Muara Bakti, Kecamatan Babelan, Kabupaten Bekasi untuk membaut baling-baling kapal dan juga merakit kapal.

PT. Cikarang Listrikindo membangun PLTU di Kecamatan Babelan yang rampung pada tahun 2017. Lokasi pembuatan PLTU di Desa Muara Bakti tak lepas dari pro dan kontar masyarakat, karena lokasi awal PLTU seharusnya berada di Desa Hurip Jaya Kecamatan Babelan yang jauh dari rumah-rumah penduduk yang tertuang dalam peraturan daerah No 12 Tahun 2011 tentang Rencana Tata Ruang Wilayah (RTRW) Kabupaten Bekasi.

\section{Dampak Pembangunan Modern Terhadap Situs Buni}

Pembangun Modern yang bersebelahan langsung dengan Situs Buni adalah pabrik kapal yang dikelola oleh PT. Tesco Indomaritim yang berlokasi di sebelah utara Situs Buni dan PLTU (Pembangkit Listri Tenaga Uap) yang dikelola oleh PT.Cikarang Listrikindo yang ada di Selatan Situs Buni. Sebagai situs yang belum dimasukan dalam Situs Cagar Budaya, Situs Buni belum bisa diakui baik sebagai Situs Cagar Budaya daerah, Situs Cagar Budaya Provinsi atau pun Situs Cagar Budaya Nasional. Situs Buni sudah pernah dilakukan penelitian oleh Lembaga Purbakala dan Peninggalan Nasional (sekarang berganti namamenjadi Pusat Penelitian Arkeologi Nasional) pada tahun 1960 yang diteliti oleh R.P Soejono dan Basuki, penelitian 1964,1969 dan 1970 oleh Sutayasa dan yang terakhir oleh Prof. DR. Hasan Djafar pada tahun 2016 (Djafar, 2016)

Peraturan Daerah Kabupaten Bekasi no.12 Tahun 2011 tentang Rencana Tata Ruang Wilayah (RTRW) Tahun 20112031 pasal 14 ayat 3 menyatakan bahwa rencana pengembangan pelayanan energi yang meliputi pipa minyak dan gas bumi sebagaimana dimaksud dalam pasal 14 ayat (1) pada poin b adalah (a). pengembangan sistem jaringan pipa minyak dan gas bumi melalui sepanjang sempadan sungai Cikarang Bekasi Luat (CBL), saluran sekunder, ladang minyak Tambun dan saluran induk Tarum Barat dan Pondok Makmur dan lainnya. Lalu pada poin (d). Pemanfaatan gas alam meliputi: 1. Stasiun Pengangkutan dan Pengisian Bulk Elpiji (SPPBE) di Kecamatan Cikarang Utara dan lainnya; 2. Liquefied Natural Gas (LNG) Terminal di Kecamatan Muaragembong; 3. Pembangkit Listrik Tenaga Gas dan Uap (PLTGU) di Muara Tawar Kecamatan Tarumajaya; 4. Liquefied Petroleum Gas (LPG) Plant di Desa Hurip Jaya di Kecamatan Babelan; dan 5. Pembangkit Listrik Tenaga Batubara Desa Hurip Jaya Kecamatan Babelan. Pada pasal 32

Pembangunan pabrik kapal dan PLTU yang bersebelahan dengan Situs Buni, membuat Situs Buni rusak akibat pembangunan. Lahan-lahan yang digunakan oleh pabrik kapal dan PLTU sebagian termasuk dan kawasan Situs Buni, karena lahan itu pernah ditemukan 
tinggalan arkeologi. Menghilannya kawasan Situs tersebut menjadikan Situs Buni menyempit dan kehilangan temuantemuan yang berpotensi tertinggal di areal pabrik kapal dan PLTU tersebut (Simoen, 2000:33).

Bagian selatan dari pabrik kapal yang dikeola oleh PT. Tesco Indomaritim merupakan tempat ditemukannya bendabenda arkeologi yang pertama kali di Situs Buni pada tahun 1960, sebelum Situs Buni dijadikan tempat penggalian liar oleh masyarakat.

Situs Buni saat ini tidak terlihat sebagai situs arkeologi, tidak adanya papan petunjuk yang menjelaskan bahwa daerah tersebut merupakan Situs Arkeologi maupun petunjuk jalan menuju Situs Buni. Tidak adanya penetapan Situs Buni sebagai Situs Cagar Budaya membuat Situs Buni tidak mendapatkan perlindungan hukum apabila terjadi hal yang tidak diinginkan (Koestoro, 2013:98).

Pada tahun 1960-1970 Situs Buni dikenal dengan Situs Arkeologi oleh masyarakat, adanya temuan perhiasan emas dan penelitian arkeologi oleh LPPN mebuat Situs Buni dikenal masyarakat luas. Situs Buni juga dinamai menjadi Kampung Pasar Mas karena banyak perhiasan emas yang ditemukan. Pembangunan kali CBL dan ikuti pabrik kapal oleh PT. Tesco Indomaritim membuat pamor dari Situs Buni meredup. Pembangunan dari PLTU oleh PT. Cikarang Listrikindo juga mempengaruhi dari hilangnya identitas Situs Buni sebagai Situs Arkeologi.

\section{Pelestarian Situs Buni}

Situs Buni saat ini tidak terlihat seperti Sius Arkeologi lainnya. Penetapan Situs Buni sebagai Situs Cagar budaya belum dilaksanakan walaupun Situs Buni sudah memenuhi kriteria Situs Cagara Budaya berdasarkan UU Cagar Budaya (Adrian, 2018:25). pemerintah dan instasi terkait yaitu Kabupaten Bekasi, BPCB
Serang, Balar Bandung, masyarakat di sekitar Situs Buni, pengelola pabrik kapal dan PLTU harus saling bekerja sama untuk melestarikan sumberdaya arkeologi di Situs Buni (Sulistyant, 2014:140).

Berdasarkan analisis SWOT upaya pelestarian yang dapat dilakukan di Situs Buni adalah sosialisasi dengan masyarakat sekitar Situs Buni terkait pelestarian benda-benda arkeologi, penelitian lebih lanjut dari instansi terkait tentang Situs Buni, membentuk badan pelestarian benda arkeologi dan situs arkeologi di Situs Buni (Wasita. 2016:64), mempublikasi kepada masyarakat luas tentang keberadaan Situs Buni sebagai situs arkeologi, pengembangan kawasan Situs Buni melalui sistem zonasi, pembuatan museum di wilayah Situs Buni (Winaya, 2015:107), mengembangkan pariwisata di sekitar Kecamatan Babelan yang mencakup Situs Buni. Masyarakat sekitar kawasan Situs Buni sangat diperlukan dalam pelestarian Situs Buni dan berkejasama dengan instansi terkait. (Wibowo, 2014:68)

\section{SIMPULAN}

Berdasarkan pembahasan di atas, dapat ditarik beberapa simpulan yaitu rusak dan hilangnya Situs Buni akibat pembangunan pabrik. Pembangunan pabrik kapal dan PLTU yang bersebelahan dengan Situs Buni, membuat Situs Buni rusak akibat pembangunan. Menghilangnya identitas Situs Buni sebagai situs Arkeologi. Desa Muara Bakti yang merupakan tempat Situs Buni berada tidak lagi dikenal oleh masyarakat luas sebagai Situs Arkeologi. Situs Buni sebagai situs arkeologi memerluka status Situs Cagar Budaya agar mendapatkan perlindungan dan perhatian dari pemerintah dan masyarakat. Selain itu hasil dari analisis SWOT sebaiknya diterapkan agar upaya pelestarian Situs Buni dapat terlaksana dengan baik. 


\section{REFERENSI}

Adrian, Yosua. 2018. Kampanye Kesadaran Masyarakat Mengenai Pelestarian Cagar Budaya Berdasarkan Undang-undang Nomor 11 Tahun 2010. Kalpataru Majalah Arkeologi. Vol 27, No.1 $2018 \quad$ (15-30). Direktorat Pelestarian Cagar Budaya dan Permuseuman, Direktorat Jenderal Kebudayaan Kementerian Pendidikan dan Kebudayaan Indonesia.

Ahimsa-Putra, Heddy Shri. 2017. Pemberdayaan Masyarakat dan Pelestarian Kawasan. Borobudur Jurnal. Vol 1, No 12017 (17-23). Balai Konservasi Borobudur Magelang.

Akbar, Ali. 2007. Prasejarah Jakarta dan Sekitarnya. Jakarta: Fakultas Ilmu Pengetahuan Budaya Universitas Indonesia.

Djafar, Hasan. Eryudawan, Bambang. Soeroso. 2016. Bangunan dan Situs Cagar Budaya Di Kabupaten Bekasi. Dinas Pariwisata Budaya Pemuda dan Olahraga Kabupaten Bekasi. Bekasi.

Kabupaten Bekasi. 2011. Peraturan Daerah Tahun 2011 tentang Tata Ruang Wilayah (RTRW). Bekasi.

Koentjaraningrat. 1986. Metode-metode Penelitian Masyarakat. Jakarta: PT Gramedia.

Koestoro, Lucas Partanda. 2013. Sekilas Tentang Pengelolaan Objek Arkeologis Bagi Upaya Pelestarian Warisan Budaya. Berkala Arkeologi Sangkakala. Vol 16, No 12013 (91-102). Balai Arkeologi Sumatra Utara.
Mantitaputy. 2010. Pentingnya Museum Bagi Pelestarian Warisan Budaya dan Pendidikan Dalam Pembangunan. Kapata Arkeologi. Vol 23, No 3, November 2010 (2534). Balai Arkeologi Ambon

Nur, M. 2009. Orientasi Manajemen Sumberdaya Arkeologi di Indonesia. Papua Jurnal. Vol. 1. No.1 Juni 2009 (1-10). Jurnal Penelitian Arkeologi Papua dan Papua Barat.

Rangkuti, Freddy. 1998. Analisis SWOT Teknik Membedah Kasus Bisnis. Jakarta: PT Gramedia.

Republik Indonesia. 2010. UU Nomer 11 Tahun 2010 tentang Cagar Budaya. Sekertariat Negara. Jakarta.

Simoen, Soenorso. 2000. Dampak Hidrologis Pembangunan Waduk Kotapanjang terhadap Kompleks Candi Muara Takus di Riau. Majalah Geografi Indonesia. Vol 14, No 1 Maret 2000 (25-38). Inherent UGM Yogyakarta

Suroto, Hari. 2009. Pelestarian Sumberdaya Budaya Dalam Bingkai Otonomi Khusus Papua. Papua Jurnal. Vol. 1. No.1 Juni 2009 (25-30). Jurnal Penelitian Arkeologi Papua dan Papua Barat.

Sulistyant, Bambang. 2014. Manajemen Pengelolaan Warisan Buday: Evaluasi Hasil Penelitian Pusat Arkeologi Nasioanl. Amerta Jurnal, Vol 32, No 2 Desemeber 2014 (137-142). Pusat Penelitian Arkeologi Nasional Jakarta.

Wasita. 2016. Pelestarian Situs-situs Arkeologi di Kalimantan Selatan: Masalah Dan Solusi Pemecahannya. Naditirawidya Jurnal. Vol 10, No 12016 pp 53- 
68. Balai Arkeologi Kalimantan Selatan.

Wibowo, Agus Budi. 2014. Strategi Pelestarian Benda/Situs Cagar Budaya Berbasis Masyarakat. Borobudur Jurnal. Vol 8, No 1 2014 (58-71). Balai Konservasi Borobudur Magelang.

Winaya, Atina. 2015. Peran Museum Majapahit Sebagai Mediator Pelestarian Warisan Budaya dan Industri Pembuatan Bata. Amerta Jurnal. Vol. 33 No.2 pp 97-110. Jurnal Penelitian dan Pengembangan Arkeologi Jakarta. 